\title{
An overview of the prevalence and pattern of maxillofacial trauma in the south of Iran
}

\author{
Mahnaz Yadollahi $^{\mathbb{(}}$, Sarina Sahmeddini2 ${ }^{*}$ \\ 'Trauma Research Center, Rajaee (Emtiaz) Trauma Hospital, Shiraz University of Medical Sciences, Shiraz, Iran \\ ${ }^{2}$ Student Research Committee, Shiraz University of Medical Sciences, Shiraz, Iran
}

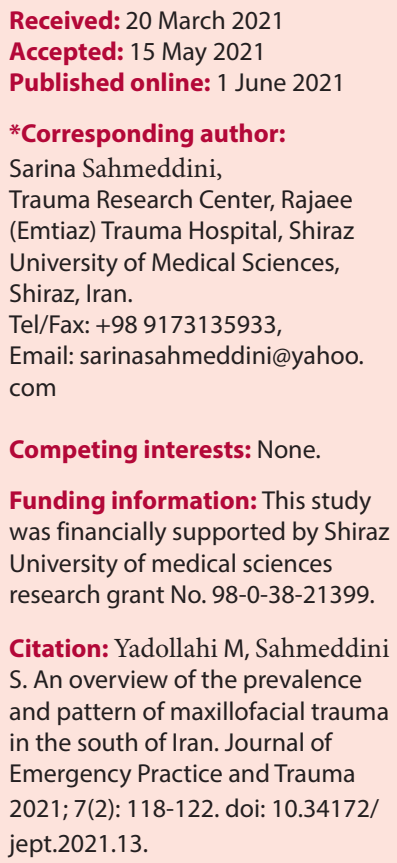

\begin{abstract}
Objective: The purpose of the current study is to determine the prevalence and pattern of maxillofacial trauma.

Methods: This is a cross sectional study of maxillofacial trauma cases treated in the referral trauma center of south of Iran. Data of 264 patients were extracted from patients records and analyzed. Data included patient's demographics, injury mechanism, types of maxillofacial injuries, Injury Severity Score (ISS), associated injuries, length of hospital stay and outcome. Binary logistic regression by backward method was applied to determine the effects of independent variables on mortality odds ratio.

Results: $85.23 \%$ of patients were males and of all patients $87.5 \%$ survived. The mean of age was $34.95 \pm 16.51$. The commonest cause of maxillofacial injury was road traffic accidents (86.31\%). The median of ISS was 20.39 10.24 and patients aged 30-39 years had the highest ISS. Overall, the most common maxillofacial injuries were orbital $(59.47 \%$, $\mathrm{n}=157)$ followed by maxillary $(48.11 \%, \mathrm{n}=127)$; common associated injuries were related to head $(81.44 \%, n=215)$ followed by thorax $(58.33 \%, n=154)$. Age and gender (being male) increased the odds ratio of mortality. An increase in ISS decreased the odds ratio of mortality, but it was not significant.

Conclusion: Most of maxillofacial trauma patients suffered from orbital injuries and there were a huge percentage of associated injuries. Gender (male), age and length of hospital stay were the significant variables of mortality in maxillofacial patients. The findings of the current study sheds light on further investigation to treat these patients and enforce road traffic legislation and public education to prevent these traumas.

Keywords: Maxillofacial injury, Multiple traumas, Traffic accidents, Injury severity score
\end{abstract}

\section{Introduction}

Maxillofacial injuries are one of the serious health complications in the world, including $7.4 \%$ to $8.4 \%$ of all emergencies $(1,2)$. Injuries of this highly neurovascular zone can lead to disability in specialized functions, substantial morbidity and even mortality. Since face plays a key role in the expression of emotions, facial trauma will have undesirable psychological effect; therefore, managing these patients is a real struggle for surgeons and has socioeconomic impacts due to the costs of hospitalization and treatment (3).

Trauma is an unavoidable part of life; epidemiologically, it is estimated that $5 \%$ to $18.5 \%$ of the whole trauma admissions are associated with maxillofacial trauma, of these $19 \%$ to $64 \%$ of patients undergo surgical repair (49). Road traffic accidents are the main causative factor of maxillofacial injuries and they are frequently associated with brain injuries $(4,7)$. By itself, maxillofacial trauma seldom threatens the life, thereby clinicians mostly focus on the other parts of the body like thorax and abdomen. However, it is mostly connected with dangerous injuries, and life-threatening complications such as blockage of the airway, thus the mortality rates can reach up to $29.4 \%$. In this regard, the minimum and maximum hospital length of stay (LOS) are reported to be 2 and 85 days, respectively (7,9-13). Although too many studies have been done around the world and since the causes and patterns of maxillofacial trauma due to cultural, environmental and legislative factors differ worldwide, there is a need for such studies to be done in each part of every country. In Iran several researches have been done mostly in the north of the country (14-17), therefore there was a certain need to investigate the incidence, pattern, etiology and severity of maxillofacial trauma in the south of Iran. Analysis of these records helps to prevent the prevalence and associated factors related to maxillofacial trauma. The aim of the 
current study was to determine the prevalence and pattern of maxillofacial trauma in the referral trauma center of Shiraz Medical University during 2018-2019.

\section{Methods}

This is a cross-sectional study of maxillofacial trauma cases treated in the referral trauma center of south of Iran. Prior to data collection, the ethics committee of Shiraz University of Medical Sciences approved this study with code IR.SUMS.REC.1398.1251. Following the basic principles of the Helsinki Declaration (ethical principles of medical research on humans), patients' information was recorded confidentially and informed consent was granted.

Data were extracted from the database of patients' trauma record who referred to the resuscitation department of trauma referral center in the south of Iran from June 2018 until June 2019. Totally, 264 patients with ICD-10 code S.00 to T79.7 of ages 15 and above were included in the study. Patients who had incomplete details or history, died before detailed assessment, patients with ICD-10 codes of foreign bodies (T15.0-T19.9), burns and corrosion injuries (T20.0-T32.9), environmental exposures (T33.0-T35.7, T66-T75.8) and poisonings (T36.0-T65.9) were excluded from this study. The demographics such as age and gender, date of admission, mechanism of injury (vehicle and pedestrian accident, assault, falling down, suicide, etc.) were recorded by the admission unit. In addition, type of maxillofacial injury such as ear, eye and nose injuries or fractures, maxilla and mandible fractures, multiple injuries and associated injuries (head, neck, thorax, abdomen, and extremities) were screened based on the final diagnosis followed by clinical and radiological examination.

Depend on the records, the injury severity score (ISS), was calculated. The ISS is based on AIS (Abbreviated injury scale), which is a scoring system that includes 6 regions of the body (head/neck, face, chest, abdomen, extremity, and external). The ISS can be calculated as the sum of the squares of the three highest AIS scores of the three most injured body regions (18).

Statistical analysis was accomplished in two phases of descriptive and analytic. While descriptive data was estimated using tables, diagrams, means and standard deviations, analytic data were evaluated by using Stata software version 14 and R3.4.2. Binary logistic regression by backward method was applied to determine the effects of independent variables, including age, gender, LOS and ISS on the odds ratio of mortality. $P$ value of $<0.05$ was considered to be statistically significant.

\section{Results}

Within the study period, 264 patients with maxillofacial injuries were admitted to the resuscitation department. Among the patients, $87.5 \%$ survived. The age ranged from 16 to 82 with the mean of $34.95 \pm 16.51$. Thirty-nine patients (14.77\%) were female and 225 (85.23\%) were male.

The mean length of hospital stay was $15.10 \pm 13.39$ days, ranging between 0 and 91 . The commonest cause of maxillofacial injuries was road traffic accidents (86.31\%) in which motorbike drivers (28.52\%) and pedestrians (18.63\%) were injured the most. Other causes of injury were falling down, assaults, penetration and suicide attempts (Table 1).

Overall, the most common maxillofacial injuries were orbital $(59.47 \%, \mathrm{n}=157)$ followed by maxillary $(48.11 \%$, $\mathrm{n}=127)$ and zygomatic injuries $(40.91 \%, \mathrm{n}=108)$. Ear and mouth were the least injured (Figure 1).

Figure 2 shows the distribution of age and sex. As depicted in Figure 2, patients in the age range of 20-29 $(n=69)$ were the most injured and patients in the age range of 80-89 were the least injured. ISS ranged between 0 and 50 and the maximum ISS (26.12) was related to 30-39 years old patients (Figure 3 ). We observed a median ISS of $20.39 \pm 10.24$. Nearly four fifth of the patients needed an operation and $27.65 \%$ had nosocomial infections.

Table 2 shows that the most injuries associated with maxillofacial were head injuries $(81.44 \%, \mathrm{n}=215)$ followed by thorax injuries $(58.33 \%, \mathrm{n}=154)$ and accidents caused the most injuries. Neck was injured the least (Table 2).

The obtained regression coefficient showed that the odds ratio of death in males was 3.74 times higher than that in females. Age increased the odds ratio of mortality by 0.07 . The mortality odds ratio of patients with hospital LOS of 4-30 days was lower than others. An increase in the ISS caused a decrease in the odds ratio of mortality but it was not significant (Table 3 ).

\section{Discussion}

The results of the current study revealed that despite the road improvements and increased usage of protective equipment for vehicle drivers and passengers, road traffic accidents still remain the major cause of maxillofacial and associated injuries. Nevertheless, geographic area and its

Table 1. Descriptive statistics of the patients by gender

\begin{tabular}{lccc}
\hline Variables & $\begin{array}{c}\text { Female } \\
\mathbf{n}=\mathbf{3 9}\end{array}$ & $\begin{array}{c}\text { Male } \\
\mathbf{n}=\mathbf{2 2 5}\end{array}$ & $\boldsymbol{P}$-value \\
\hline Outcome & $35(89.75)$ & $196(87.11)$ & 0.585 \\
Survived & $4(10.25)$ & $29(12.89)$ & \\
Died & & & \\
Mechanism of injury & $37(94.87)$ & $176(78.22)$ & \\
Accident & 0 & $2(0.88)$ & \\
Assault & 0 & $40(17.77)$ & 0.043 \\
Falling down & 0 & $4(1.77)$ & \\
Penetration & $1(2.56)$ & 0 & \\
Suicide & & & \\
Length of stay & $16.18 \pm 16.16$ & $14.9 \pm 12.8$ & 0.57 \\
\hline Mean \pm SD & & & \\
\hline
\end{tabular}


Table 2. The frequency of associated injuries by mechanism of injury

\begin{tabular}{lcccc}
\hline \multirow{2}{*}{$\begin{array}{c}\text { Mechanism } \\
\text { of injury }\end{array}$} & Accidents & Assault & Falling down & Penetration \\
\cline { 2 - 5 } Head & 189 & 1 & 20 & 4 \\
\hline Neck & 21 & 0 & 3 & 1 \\
Thorax & 135 & 0 & 16 & 3 \\
Abdomen & 25 & 0 & 8 & 0 \\
Extremity & 102 & 0 & 14 & 1 \\
\hline
\end{tabular}

Table 3. Logistic regression coefficients and odds ratios of the variables of mortality between trauma patients

\begin{tabular}{|c|c|c|c|}
\hline Variables & Odds ratio & $95 \%$ confidence interval & $P$ value \\
\hline Age & 1.077 & (1.047-1.098) & $<0.001$ \\
\hline Sex (male) & 3.749 & $(0.88-6.453)$ & $<0.073$ \\
\hline \multicolumn{4}{|l|}{ Length of stay } \\
\hline 1 to 3 days & 0.041 & $(0.003-0.079)$ & 0.019 \\
\hline 4-7 days & 0.019 & $(0.001-0.037)$ & $<0.001$ \\
\hline 8-30 days & 0.013 & $(0.001-0.027)$ & $<0.001$ \\
\hline More than 30 days & 0.030 & $(0.002-0.058)$ & $<0.001$ \\
\hline Injury severity score & 0.427 & $(0.117-0.737)$ & 0.170 \\
\hline
\end{tabular}

population density, cultural differences and economic status can affect the incidence, etiology and clinical presentation of maxillofacial injuries.

Many articles have described road traffic accidents as the leading etiologic factor in both developed and developing countries such as Italy (19), Taiwan (20), China (3), and Qatar (4), however assault (21), and falls (22), were the commonest causes of maxillofacial fractures in many other nations. As a developing country, Iran faces heavy traffic problems and traffic accidents that are on a rise year by year. Therefore, there is a need to reinforce existing laws to lessen traffic accidents in the country.

Similar to many other studies (23-25), in the current study most of the injuries were seen in males (almost $85 \%)$, most probably because men are more involved in road traffic accidents, fights, and other physical activities. In Iran, also the incidence of maxillofacial injuries was greater among men aged 20-29 years. This finding is in line with the results of a study conducted in the north of Iran indicating that the highest rate of maxillofacial incidence in trauma patients was in the age group of 20 to 29 years (26). These findings are not consistent with the study that reported the incidence of trauma in the age group of 3039 years (7). In the study of da Rosa Possebon et al (22), age and sex had a significant effect on the mortality of maxillofacial trauma $(P<0.001)$.

In the current study, the most commonly injured parts were orbits followed by maxilla. In line with our investigation, two other studies revealed that orbits followed by maxilla fractures were the most frequent type of maxillofacial injuries $(5,9)$. Nevertheless, some studies reported that mandible fracture had the highest rate of incidence (27-29). Probably the severity of injuries associated with a different ISS range is the reason of discrepancy in the results of studies. Associated injuries are frequently observed between patients who have suffered from maxillofacial injuries and are correlated with trauma mechanism and severe facial fractures (30). The current results are consistent with the findings of the studies conducted by Alves et al (7), and Aladelusi et

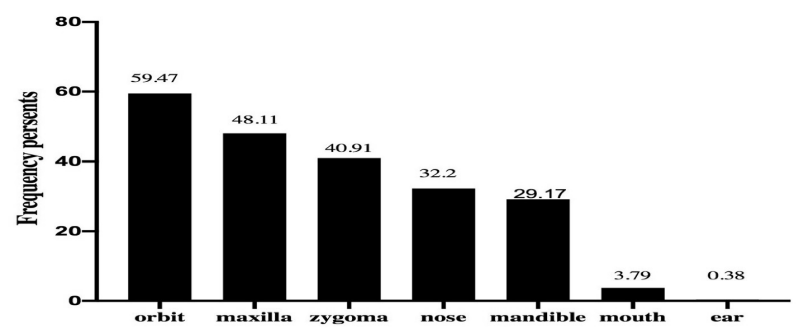

Figure 1. Type of maxillofacial injuries.

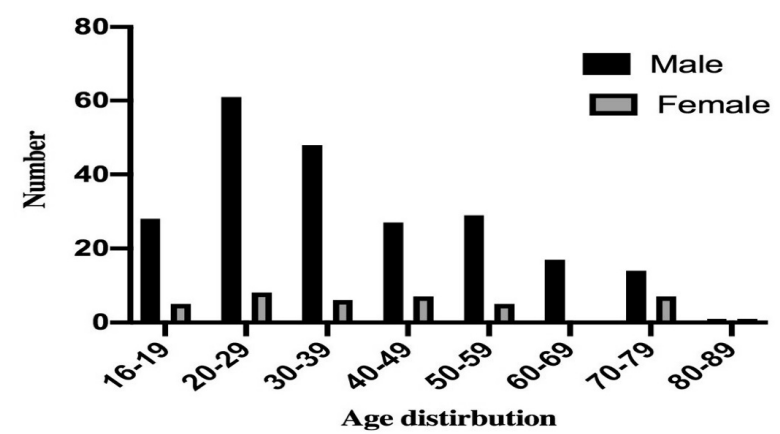

Figure 2. Distribution of age by sex. 


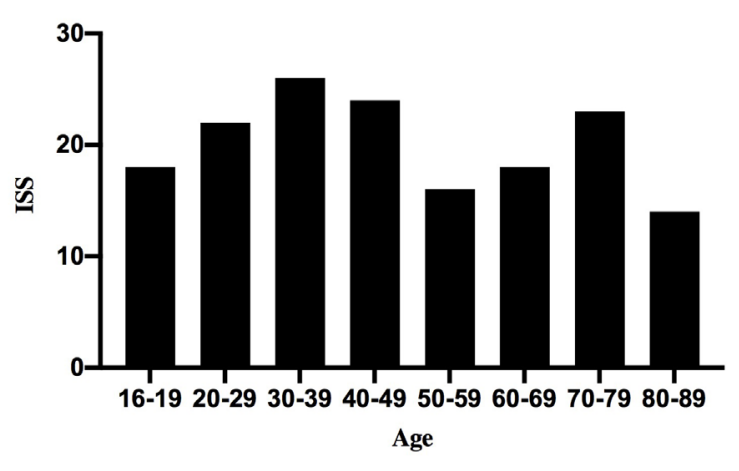

Figure 3. Descriptive statistics of ISS by age range

al (31) demonstrating that most injuries associated with maxillofacial were head injuries.

The ISS ranged between 1 and 50, and patients in their 4 th decade of life had the highest median of ISS. The median of ISS was 13 . There was no statistically significant association between the ISS and mortality rate $(P=0.17)$. Lower severity scores may determine that severely injured patients passed away earlier to any assessment of their injuries. Besides, any mistake in AIS scoring will result in modification of the ISS (11). Death occurred in $12.5 \%$ of injuries. In other studies, mortality rates were $1.8 \%$ and $10.5 \%$. This can be due to concomitant non-facial injuries such as pulmonary and neurologic injuries $(11,12)$. The length of hospital stay ranged between 0 and 91 and LOS of women was more than men. The research finding concerning the hospital stay in the study conducted by Manodh et al in 2016 (32) revealed that $48.35 \%$ of patients were treated in less than 4 days after the trauma.

This study has its own limitations regarding the missing of information and selection bias. Nonetheless, our study provides useful information concerning the development of safety measures to reduce the chance of maxillofacial injuries. We recommend conducting further researches in Iran to assess the effect of other factors, including seat belts and alcohol consumption on the maxillofacial traumas.

\section{Conclusion}

Road traffic accidents were the main cause of orbital and maxillary injuries. Male gender, age, and length of hospital stay were the significant variables of mortality in maxillofacial trauma. Furthermore, we have to consider a huge percentage of associated injuries with maxillofacial trauma. Therefore, further diagnostic investigations should play a part in the assessment of maxillofacial trauma patients. According to our study, road traffic legislation and public education should be enforced.

\section{Ethical issues}

The ethics committee of Shiraz university of medical sciences approved this study with code IR.SUMS. REC.1398.1251. According to the basic principles of the Helsinki Declaration (ethical principles of medical research on humans), patients' information was recorded confidentially and patients provided informed consent.

\section{Author's contribution}

MY: study concept, investigation, methodology, project administration, validation, writing and editing. SS: investigation, methodology, writing the original draft. all authors have approved the final version

\section{Acknowledgement}

The authors would like to express our gratitude and appreciation to Forough Pazhuheian (Trauma research center, Rajaee (Emtiaz), Shiraz, Iran) for her help in collecting data and statistical advice.

\section{References}

1. Nóbrega LM, Cavalcante GM, Lima MM, Madruga RC, Ramos-Jorge ML, d'Avila S. Prevalence of facial trauma and associated factors in victims of road traffic accidents. Am J Emerg Med 2014;32(11):1382-1386. doi:10.1016/j. ajem.2014.08.054

2. Wulkan M, Parreira JG Jr, Botter DA. Epidemiology of facial trauma. Rev Assoc Med Bras 2005;51(5):290-295. doi:10.1590/s0104-42302005000500022

3. Mijiti A, Ling W, Tuerdi M, Maimaiti A, Tuerxun J, Tao YZ, et al. Epidemiological analysis of maxillofacial fractures treated at a university hospital, Xinjiang, China: a 5-year retrospective study. J Craniomaxillofac Surg 2014;42(3):227-233. doi:10.1016/j.jcms.2013.05.005

4. Al-Hassani A, Ahmad K, El-Menyar A, Abutaka A, Mekkodathil A, Peralta R, et al. Prevalence and patterns of maxillofacial trauma: a retrospective descriptive study. Eur J Trauma Emerg Surg 2019. doi:10.1007/s00068-01901174-6

5. Scheyerer MJ, Döring R, Fuchs N, Metzler P, Sprengel K, Werner CML, et al. Maxillofacial injuries in severely injured patients. J Trauma Manag Outcomes 2015;9:4. doi:10.1186/ s13032-015-0025-2

6. Goodisson D, MacFarlane M, Snape L, Darwish B. Head injury and associated maxillofacial injuries $\mathrm{N} \mathrm{Z} \mathrm{Med} \mathrm{J.}$ 2004;117(1201):U1045.

7. Alves LS, Aragão I, Sousa MJ, Gomes E. Pattern of maxillofacial fractures in severe multiple trauma patients: a 7-year prospective study. Braz Dent J 2014;25(6):561-564. doi:10.1590/0103-6440201302395

8. Martini MZ, Takahashi A, de Oliveira Neto HG, de Carvalho Júnior JP, Curcio R, Shinohara EH. Epidemiology of mandibular fractures treated in a Brazilian level I trauma public hospital in the city of São Paulo, Brazil. Braz Dent J 2006;17(3):243-248. doi:10.1590/s010364402006000300013

9. Keller MW, Han PP, Galarneau MR, Gaball CW. Characteristics of maxillofacial injuries and safety of intheater facial fracture repair in severe combat trauma. Mil Med 2015;180(3):315-320. doi:10.7205/milmed-d-14-00345

10. Down KE, Boot DA, Gorman DF. Maxillofacial and associated injuries in severely traumatized patients: implications of a regional survey. Int J Oral Maxillofac Surg 1995;24(6):409-412. doi:10.1016/s0901-5027(05)80469-2 
11. Béogo R, Savadogo LBG, Dakouré PWH, Coulibaly AT, Ouoba K. Injury severity in patients with facial fractures and concomitant injuries. Med Buccale Chir Buccale 2014;20(2):85-88. doi:10.1051/mbcb/2014003

12. Shahim FN, Cameron P, McNeil JJ. Maxillofacial trauma in major trauma patients. Aust Dent J 2006;51(3):225-230. doi:10.1111/j.1834-7819.2006.tb00433.x

13. Bocchialini G, Castellani A. Facial trauma: a retrospective study of 1262 patients. Ann Maxillofac Surg 2019;9(1):135139. doi:10.4103/ams.ams_51_19

14. Mesgarzadeh AH, Shahamfar M, Feizi Azar S, Shahamfar J. Analysis of the pattern of maxillofacial fractures in north western of Iran: a retrospective study. J Emerg Trauma Shock 2011;4(1):48-52. doi:10.4103/0974-2700.76837

15. Samieirad S, Aboutorabzade MR, Tohidi E, Shaban B, Khalife H, Hashemipour MA, et al. Maxillofacial fracture epidemiology and treatment plans in the Northeast of Iran: a retrospective study. Med Oral Patol Oral Cir Bucal 2017;22(5):e616-e624. doi:10.4317/medoral.21809

16. Kalantar Motamedi MH, Dadgar E, Ebrahimi A, Shirani G, Haghighat A, Jamalpour MR. Pattern of maxillofacial fractures: a 5-year analysis of 8,818 patients. J Trauma Acute Care Surg 2014;77(4):630-634. doi:10.1097/ ta.0000000000000369

17. Sheikhmotahar Vahedi H, Vahidi E, Basirian R, Saeedi M. Assessment of maxillofacial trauma in the emergency department. Trauma Mon 2017;22(6):e58204. doi:10.5812/ traumamon.58204

18. Baker SP, O'Neill B, Haddon W Jr, Long WB. The injury severity score: a method for describing patients with multiple injuries and evaluating emergency care. J Trauma 1974;14(3):187-196.

19. Bonavolontà $P$, Dell'aversana Orabona $G$, Abbate V, Vaira LA, Lo Faro C, Petrocelli M, et al. The epidemiological analysis of maxillofacial fractures in Italy: the experience of a single tertiary center with 1720 patients. J Craniomaxillofac Surg 2017;45(8):1319-1326. doi:10.1016/j.jcms.2017.05.011

20. Lu Y, Shen H, Wang J, Lu X. Characteristics on 621 cases of craniomaxillofacial fractures. Eur J Trauma Emerg Surg 2019;45(5):893-900. doi:10.1007/s00068-018-0950-7

21. Cohn JE, Smith KC, Licata JJ, Michael A, Zwillenberg $\mathrm{S}$, Burroughs $\mathrm{T}$, et al. Comparing urban maxillofacial trauma patterns to the National Trauma Data Bank@. Ann Otol Rhinol Laryngol 2020;129(2):149-156. doi:10.1177/0003489419878457

22. da Rosa Possebon A, Granke G, Faot F, de Rezende Pinto L, Leite FRM, Torriani MA. Etiology, diagnosis, and demographic analysis of maxillofacial trauma in elderly persons: a 10-year investigation. J Craniomaxillofac Surg 2017;45(12):1921-1926. doi:10.1016/j.jcms.2017.09.002
23. Lee CW, Foo QC, Wong LV, Leung YY. An overview of maxillofacial trauma in oral and maxillofacial tertiary trauma centre, Queen Elizabeth hospital, Kota Kinabalu, Sabah. Craniomaxillofac Trauma Reconstr 2017;10(1):1621. doi:10.1055/s-0036-1584893

24. Schneider D, Kämmerer PW, Schön G, Dinu C, Radloff S, Bschorer R. Etiology and injury patterns of maxillofacial fractures from the years 2010 to 2013 in MecklenburgWestern Pomerania, Germany: a retrospective study of 409 patients. J Craniomaxillofac Surg 2015;43(10):1948-1951. doi:10.1016/j.jcms.2015.06.028

25. Rao SG, Paramesh RC, Bansal A, Shukla D, Sadashiva N, Saini J. A prospective computed tomography study of maxillofacial injuries in patients with head injury. Eur J Trauma Emerg Surg 2019. doi:10.1007/s00068-019-010990

26. Akhlaghi F, Mafi N, Bastami F. Prevalence of maxillofacial fractures and related factors: a five-year retrospective study. Trauma Mon 2019;24(4):1-4. doi:10.5812/ traumamon.83974

27. van den Bergh B, Karagozoglu KH, Heymans MW, Forouzanfar T. Aetiology and incidence of maxillofacial trauma in Amsterdam: a retrospective analysis of 579 patients. J Craniomaxillofac Surg 2012;40(6):e165-169. doi:10.1016/j.jcms.2011.08.006

28. Prasad C, Narayanan MB, Parimala V, Vijjaykanth M. Prevalence and pattern of maxillofacial trauma in North Chennai: A retrospective study. J Indian Assoc Public Health Dent 2018;16(4):303-307. doi:10.4103/jiaphd. jiaphd_60_18

29. Scherbaum Eidt JM, De Conto F, De Bortoli MM, Engelmann JL, Rocha FD. Associated injuries in patients with maxillofacial trauma at the hospital são vicente de paulo, passo fundo, Brazil. J Oral Maxillofac Res 2013;4(3):e1. doi:10.5037/jomr.2013.4301

30. Thorén H, Snäll J, Salo J, Suominen-Taipale L, Kormi E, Lindqvist C, et al. Occurrence and types of associated injuries in patients with fractures of the facial bones. J Oral Maxillofac Surg 2010;68(4):805-810. doi:10.1016/j. joms.2009.09.057

31. Aladelusi T, Akinmoladun V, Olusanya A, Akadiri O, Fasola A. Analysis of road traffic crashes-related maxillofacial injuries severity and concomitant injuries in 201 patients seen at the UCH, Ibadan. Craniomaxillofac Trauma Reconstr 2014;7(4):284-289. doi:10.1055/s-0034-1378183

32. Manodh P, Prabhu Shankar D, Pradeep D, Santhosh $\mathrm{R}$, Murugan A. Incidence and patterns of maxillofacial trauma-a retrospective analysis of 3611 patients-an update. Oral Maxillofac Surg 2016;20(4):377-383. doi:10.1007/ s10006-016-0576-z 